\title{
Evaluation of the Sensitivity of USP Prednisone Tablets to Dissolved Gas in the Dissolution Medium Using USP Apparatus 2
}

\author{
Pallavi Nithyanandan ${ }^{1,2}$, Gang Deng ${ }^{1}$, William Brown ${ }^{1}$, \\ Ronald Manning ${ }^{1}$, and Samir Wahab ${ }^{1}$
}

\begin{abstract}
This study evaluated the sensitivity of USP Prednisone tablets (Reference Standard Lot POE203) to dissolved gas in the medium in USP Apparatus 2. This lot will be introduced into commerce over the summer of 2006 as a replacement for current Lot O0C056. The effect of deaeration techniques and water purification methods on dissolution was also studied. Dissolution tests were performed in water containing nine different concentrations of dissolved gas. The oxygen and total dissolved gas pressure was monitored using a dissolved gas and oxygen meter. Other experimental variables such as the equipment, shaft position, and vessel position were kept constant throughout the study. The same analyst performed all studies. The study tablets were highly sensitive to dissolved gas in USP Apparatus 2 . An increase in both the amount of prednisone dissolved and the variability of results was observed when the dissolved oxygen concentration exceeded $6 \mathrm{mg} / \mathrm{L}$. The corresponding sum of the partial pressure of gases other than oxygen and the percent saturation were $510 \mathrm{~mm} \mathrm{Hg}$ and $68 \%$, respectively.
\end{abstract}

\section{Introduction}

The level of dissolved gas in the dissolution medium is known to have a significant impact on the dissolution of some drug products $(1,2)$. Aberrant dissolution results can often be attributed to improper deaeration of the dissolution medium (2-4). Although some drug products are known to be extremely sensitive to dissolved gas, the presence of air bubbles should be expected to increase the measurement uncertainty in dissolution testing. In USP Apparatus 2, released air bubbles deposit on the paddle shaft, the surface of the medium, and have been observed adhering to disintegrating drug particles. The release of air bubbles alters the hydrodynamics of the system by changing the fluid flow characteristics in the dissolution vessel $(5,6)$. The presence of dissolved gases also is suspected, in many cases, of failure to meet apparatus suitability standards $(2,5)$.* Previous studies have demonstrated the use of dissolved oxygen as a measure of deaeration (7-10), although some indicate that dissolved oxygen alone is not an adequate measure (11) with recommendations that other gases, particularly nitrogen and carbon dioxide, should be measured and controlled as well. In this study, oxygen as well as the total dissolved gas pressure (the sum of the partial pressures of oxygen, nitrogen, argon, carbon dioxide, and other trace gases) was monitored from the time the medium was transferred into the dissolution vessel until the end of the dissolution test.

\section{Experimental}

Nine dissolution media encompassing a range of dissolved oxygen (1.38-10.08 mg/L) and total dissolved gas

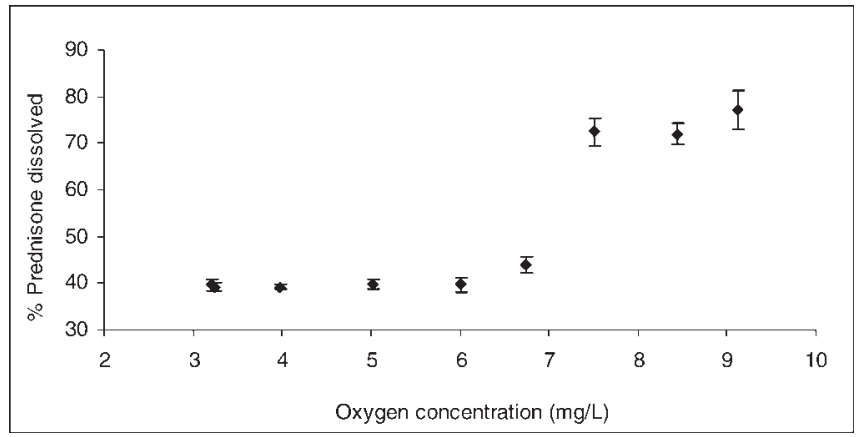

Figure 1. Effect of dissolved oxygen concentration on percent prednisone dissolved in $30 \mathrm{~min}$.

concentrations were tested. The ranges of dissolved gases were selected based on possible levels that could be encountered by dissolution practitioners using different deaeration techniques and water purified by various methods. Deaeration techniques included the USP technique, the FDA technique, and helium sparging. Water samples purified by de-ionization and by the Milli-Q system were also evaluated. Different levels of dissolved gas in test media were obtained by mixing media that contained various levels of dissolved gas (Table 1) (12). Experimental variables such as the equipment, shaft position, and vessel position were held constant throughout the study. The same analyst performed all studies.

\section{Measurement of dissolved gas \\ Dissolved oxygen and total dissolved gas were measured using a Dissolved Gas and Oxygen Meter (Model TBO-DL6,}

'United States Pharmacopeia, 12601 Twinbrook Parkway, Rockville, MD 20852-1790

${ }^{2}$ Corresponding author.
*USP is in the process of clarifying the status of the apparatus suitability test using chemical tablets as a Performance Verification Test (PVT).

Forthcoming papers will explore this topic in greater detail. 
Table 1. Prednisone dissolution as a function of dissolved gas level in the dissolution medium

\begin{tabular}{|c|c|c|c|c|c|c|c|c|}
\hline \multirow{2}{*}{$\begin{array}{l}\text { Dissolution } \\
\text { medium }^{b}\end{array}$} & \multicolumn{3}{|c|}{ Oxygen concentration (mg/L) } & \multicolumn{3}{|c|}{$\begin{array}{c}\text { Combined pressure of gases other than } \\
\text { oxygen }(\mathrm{mm} \mathrm{Hg})\end{array}$} & \multicolumn{2}{|c|}{$\begin{array}{l}\text { Percentage of Prednisone } \\
\text { dissolved }^{\mathrm{a}}\end{array}$} \\
\hline & $\begin{array}{c}\text { Medium } \\
\text { transferred } \\
\text { to vessels }\end{array}$ & $\begin{array}{l}\text { Beginning } \\
\text { of test }\end{array}$ & End of test & $\begin{array}{l}\text { Medium } \\
\text { transferred } \\
\text { to vessels }\end{array}$ & $\begin{array}{l}\text { Beginning } \\
\text { of test }\end{array}$ & End of test & Mean \pm SD & $\%$ RSD $^{c}$ \\
\hline 1 & $2.18 \pm 1.06$ & $3.21 \pm 0.61$ & $4.77 \pm 0.28$ & $375 \pm 69$ & $335 \pm 60$ & $392 \pm 65$ & $39.6 \pm 1.2$ & 3.0 \\
\hline 2 & $1.95 \pm 0.34$ & $3.25 \pm 0.60$ & $4.64 \pm 0.66$ & $586 \pm 82$ & $326 \pm 94$ & $395 \pm 85$ & $39.2 \pm 0.9$ & 2.2 \\
\hline 3 & $2.59 \pm 0.54$ & $3.97 \pm 0.74$ & $4.99 \pm 0.08$ & $667 \pm 21$ & $450 \pm 52$ & $443 \pm 25$ & $39.2 \pm 0.9$ & 2.3 \\
\hline 4 & $1.81 \pm 0.32$ & $5.02 \pm 0.51$ & $6.53 \pm 0.52$ & $702 \pm 35$ & $510 \pm 18$ & $502 \pm 11$ & $39.7 \pm 1.4$ & 3.4 \\
\hline 5 & $4.05 \pm 0.75$ & $6.01 \pm 0.10$ & $7.06 \pm 0.30$ & $548 \pm 37$ & $394 \pm 27$ & $468 \pm 22$ & $39.6 \pm 1.5$ & 3.8 \\
\hline 6 & $6.06 \pm 0.35$ & $6.74 \pm 0.25$ & $6.94 \pm 0.38$ & $621 \pm 13$ & $575 \pm 41$ & $590 \pm 6$ & $44.0 \pm 1.8$ & 4.2 \\
\hline 7 & $7.23 \pm 0.31$ & $7.51 \pm 0.23$ & $7.75 \pm 0.20$ & $620 \pm 4$ & $611 \pm 2$ & $607 \pm 1$ & $72.4 \pm 3.1$ & 4.3 \\
\hline 8 & $8.37 \pm 0.33$ & $8.44 \pm 0.13$ & $8.51 \pm 0.09$ & $598 \pm 9$ & $597 \pm 5$ & $595 \pm 4$ & $71.9 \pm 2.3$ & 3.2 \\
\hline 9 & $10.08 \pm 1.09$ & $9.13 \pm 0.23$ & $9.01 \pm 0.28$ & $592 \pm 11$ & $613 \pm 19$ & $599 \pm 8$ & $77.2 \pm 4.1$ & 5.4 \\
\hline \multicolumn{9}{|c|}{$\begin{array}{l}\text { a Results are expressed as mean } \pm \text { standard deviation }(S D), n=3 ; 6 \text { tablets were analyzed in each dissolution test. } \\
\text { b Dissolution medium:(1)= Milli-Q water deaerated per USP procedure, }(2)=\text { Deionized water deaerated per USP procedure, }(3)=1: 1 \text { mix- } \\
\text { ture of non-deaerated Milli-Q water and Milli-Q water deaerated per USP procedure, }(4)=\text { Milli-Q water deaerated by helium sparging for } \\
30 \text { minutes at } 6 \text { psi, }(5)=\text { Milli-Q water deaerated per FDA procedure, }(6)=\text { Non-deaerated Milli-Q water, }(7)=1: 1 \text { mixture of non-deaerated } \\
\text { deionized water and non-deaerated Milli-Q water, }(8)=\text { Non-deaerated deionized water, and, }(9)=\text { Non-deaerated Milli-Q water sparged } \\
\text { with air. } \\
{ }^{c} \text { Relative standard deviation }\end{array}$} \\
\hline
\end{tabular}

Common Sensing Inc., Clark Fork, ID). The meter contained two probes, one for oxygen and the other for total dissolved gas. Constant stirring was required to ensure proper operation of the oxygen probe. Dissolved gas levels were recorded at 1-min intervals, and data were downloaded into a spreadsheet.

\section{Deaeration techniques}

USP technique: Purified Milli-Q water was heated to about $41{ }^{\circ} \mathrm{C}$ with gentle stirring. A vacuum of $60 \mathrm{mbar}$ was generated using a water aspirator (Model B-169, Brinkman Instruments, Westbury, NY) and monitored with an in-line vacuum gauge (Vacuubrand, Essex, CT). Medium was filtered under vacuum using a $0.45-\mu \mathrm{m}$ membrane filter (Millipore Corporation, Billerica, $\mathrm{MA}$ ) with vigorous stirring. Stirring continued for 5 min under vacuum following filtration (13).

FDA technique: Air was bubbled through the medium under a reduced pressure of $140-150 \mathrm{~mm} \mathrm{Hg}$ (14).

Helium sparging:The medium was sparged with helium (Airgas Inc., Radnor, PA) via a solvent inlet filter at a pressure of 6 psi for $30 \mathrm{~min}$ (12).

\section{Dissolution}

Dissolution tests were performed at $37^{\circ} \mathrm{C}$ using USP Apparatus 2 at 50 rpm (Hanson SR8 Plus Dissolution Test
Station, Chatsworth, CA). Water (500 mL) was used as the dissolution medium. At each dissolved gas level, three replicate dissolution runs were performed with a set of six tablets for each run. At $30 \mathrm{~min}, 30-\mathrm{mL}$ samples were manually collected. The samples were filtered using a $0.45-\mu \mathrm{m}$ syringe filter (Millipore Corporation, Billerica, MA) discarding the first $5 \mathrm{~mL}$. Relative prednisone concentrations were

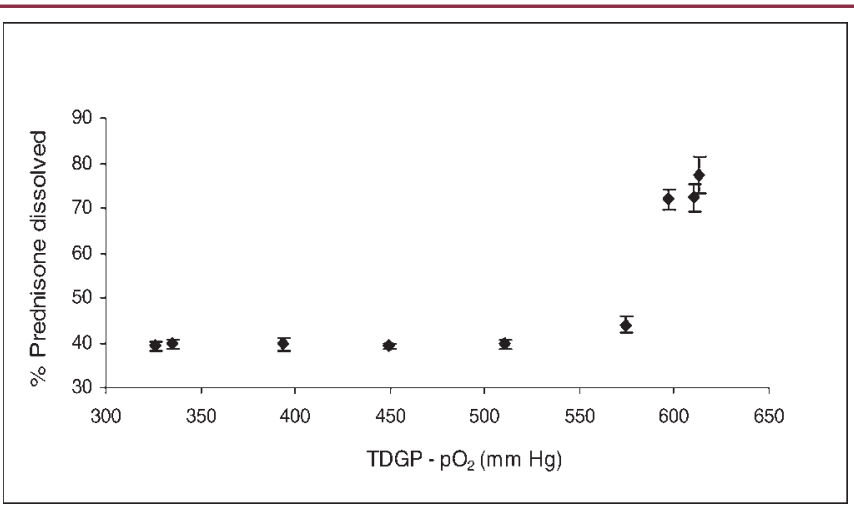

Figure 2. Effect of dissolved gases other than oxygen on percent prednisone dissolved in $30 \mathrm{~min}$. These values were obtained by subtracting the partial pressure of oxygen $\left(\mathrm{pO}_{2}\right.$ ) from the total dissolved gas pressure (TDGP).TDGP $-p \mathrm{O}_{2}$ is a measure of the combined pressures of nitrogen, argon, water vapor, carbon dioxide, and other trace gases. 
determined by comparison with solutions made from USP Prednisone Reference Standard (Lot MOD211) using UV analysis at $242 \mathrm{~nm}$ (Perkin Elmer Instruments, Wellesley, MA). Dissolution results were calculated as a percentage of the label claim dissolved. The label claim was $10 \mathrm{mg}$ prednisone per tablet.

\section{Results}

The dissolved oxygen concentration, combined pressures of gases other than oxygen (total dissolved gas pressure minus the partial pressure of oxygen, TDGP $-\mathrm{pO}_{2}$ ), and the corresponding percent prednisone dissolved values are summarized in Table 1. The TDGP $-\mathrm{pO}_{2}$ values were obtained by subtracting the partial pressure of oxygen $\left(\mathrm{pO}_{2}\right)$ from the total dissolved gas pressure (TDGP). This value is reflective of the combined pressures of nitrogen, argon, carbon dioxide, and other trace gases in the medium. The results indicate a dissolved oxygen sensitivity threshold concentration of about $6 \mathrm{mg} / \mathrm{L}$, above which both the amount dissolved and variability of results increased (Figure 1). The corresponding total dissolved gas pressure, excluding dissolved oxygen, was about $510 \mathrm{~mm}$ $\mathrm{Hg}$ (Figure 2). The percent saturation at this level was $68 \%$. The three different deaeration techniques produced similar dissolution results despite differences in their efficiency. The reaeration profiles are illustrated in Figures 3 and 4. The times required for media to reach the bath temperature of $37^{\circ} \mathrm{C}$ were 13,28 , and 38 min for the USP, FDA, and helium sparging techniques, respectively. For helium sparging, the dissolved oxygen level increased from 1.81 to $5.02 \mathrm{mg} / \mathrm{L}$ from the time the medium was transferred to the vessels to the start of the dissolution test. During this equilibration time, the TDGP $-\mathrm{pO}_{2}$ decreased, perhaps due to the release of helium from the medium. Significantly higher percent dissolved values were obtained in non-deaerated, deionized water compared to those obtained in non-deaerated Milli-Q water $(p \leq 0.01)$. The results were consistent with previous studies suggesting that $4-7 \mathrm{mg} / \mathrm{L}$ of dissolved oxygen

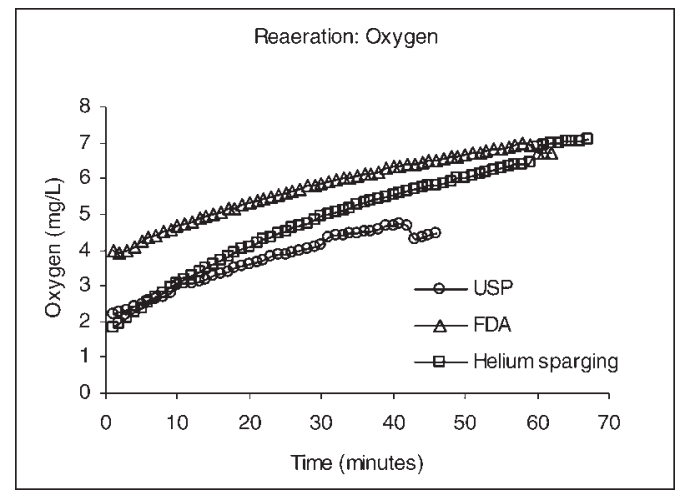

Figure 3. Reaeration profiles for dissolution medium deaerated by the USP technique, FDA technique, and helium sparging. Oxygen levels were recorded from the time the medium was weighed into the dissolution vessels (time $=0 \mathrm{~min}$ ) until the end of the 30-min dissolution test.

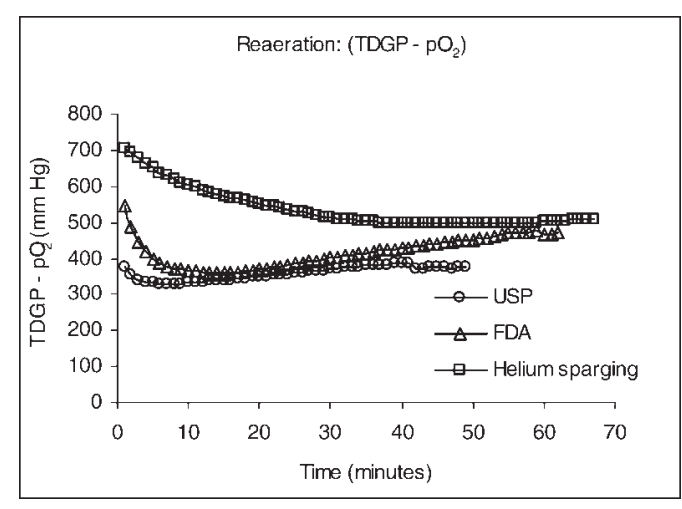

Figure 4. Reaeration profiles for dissolution medium deaerated by the USP technique, FDA technique, and helium sparging. Total dissolved gas pressure (TDGP) $-\mathrm{pO}_{2}$ is a measure of the combined pressures of nitrogen, argon, water vapor, carbon dioxide, and other trace gases. Dissolved gas levels were recorded from the time the medium was weighed into the dissolution vessels (time $=0 \mathrm{~min}$ ) until the end of the 30 -min dissolution test.

produced an equilibrium effect (7). The oxygen probe provided instantaneous stable readings within 1-2 min, but the total dissolved gas probe required about $10 \mathrm{~min}$.

\section{Conclusions}

USP Prednisone Tablets (Reference Standard Lot POE203) used for the USP Performance Verification Test (PVT) are sensitive to dissolved oxygen and total dissolved gas in USP Dissolution Apparatus 2. An increase in the amount of prednisone dissolved and a slight increase in the variability of results were observed beyond an apparent oxygen sensitivity threshold level of about $6 \mathrm{mg} / \mathrm{L}$. The corresponding percent saturation was $68 \%$. Although heating the medium prior to deaeration does not affect the efficiency of deaeration, it minimizes reaeration by reducing the time required to heat the medium to $37^{\circ} \mathrm{C}$ after transfer to the dissolution vessel. These results highlight the importance of knowing the dissolved gas content of the water source in the laboratory. The data also suggest that dissolved oxygen has a significant influence on dissolution. However, the measurement of dissolved oxygen alone may not be adequate when inert gas sparging is being used to deaerate dissolution media. The measurement of total dissolved gas is necessary when inert gas sparging is being used.

\section{References}

1. Dissolution Testing of Immediate-Release Solid Oral Dosage Forms. Guidance for Industry; U.S. Department of Health and Human Services, Food and Drug Administration, Center for Drug Evaluation and Research, U.S. Government Printing Office: Washington, DC, 1997.

2. Qureshi, S. A.; McGilveray, I. J. Typical variability in drug dissolution testing: study with USP and FDA calibrator tablets and a marketed drug (glibenclamide) product. Eur. J. Pharm. Sci. 1999, 7, 249-258. 
3. Qureshi, S. A.; McGilveray, I. J. Impact of different deaeration methods on the USP dissolution apparatus suitability test criteria. Pharm. Forum. 1994, 8565-8566.

4. Grady, L. T. Dissolution calibrators used by the United States Pharmacopeia. Pharm. Forum. 1994, 20, 8567-8570.

5. Hanson, R.; Gray, V. Handbook of Dissolution Testing, 3rd ed.; Dissolution Technologies: Hockessin, DE, 2004.

6. Lindauer, R. F. USP dissolution calibrator tablets-is it time to reduce the amount of testing required to calibrate apparatus 1 and 2? Pharm. Forum. 1995, 21, 1397-1402.

7. Curley, T.; Forsyth, R.; Sun, S.; Fliszar, K.; Colletto, M.; Martin, G. P. Measurement of dissolved oxygen as a determination of media equilibrium during dissolution testing. Dissolution Technol. 2004, 11 (4), 6-11.

8. Diebold, S. M.; Dressman, J. B. Dissolved oxygen as a measure for de- and reaeration of aqueous media for dissolution testing. Dissolution Technol. 1998, 5 (3), 13-16.

9. Rohrs, B. R.; Stelzer, D. J. Deaeration techniques for dissolution media. Dissolution Technol. 1995, 2 (2), 6-8.
10. Degenhardt, O. S.; Waters, B.; Rebelo-Cameirao, A.; Meyer, A.; Brunner, H.; Toltl, N. P. Comparison of the effectiveness of various deaeration techniques. Dissolution Technol. 2004, 11 (1), 6-11.

11. Gao, Z.; Moore, T. W.; Doub, W. H.; Westenberger, B. J.; Buhse, L. F. Effects of deaeration methods on dissolution testing in aqueous media: A study using a total dissolved gas pressure meter. J. Pharm. Sci. 2006, 95, 1606-1613.

12. Bempong, D. E.; Adkins, R. E.; Bradby, S.; Graves, R. M.; Lopez, E. I.; Sanchez, A. L.; Bhattacharya, L.; Manning, R. G. Perturbation study 1: Effect of dissolved air on the dissolution of the proposed lot N USP prednisone tablets (dissolution calibrator disintegrating) RS. USP internal project report, 2001.

13. Physical tests and determinations, General Chapter <711> Dissolution. United States Pharmacopeia 29; United States Pharmacopeial Convention, Inc.: Rockville, MD, 2005.

14. Moore, T. W. Dissolution testing: a fast, efficient procedure for degassing dissolution medium. Dissolution Technol. 1996, 3 (2), 3-5.

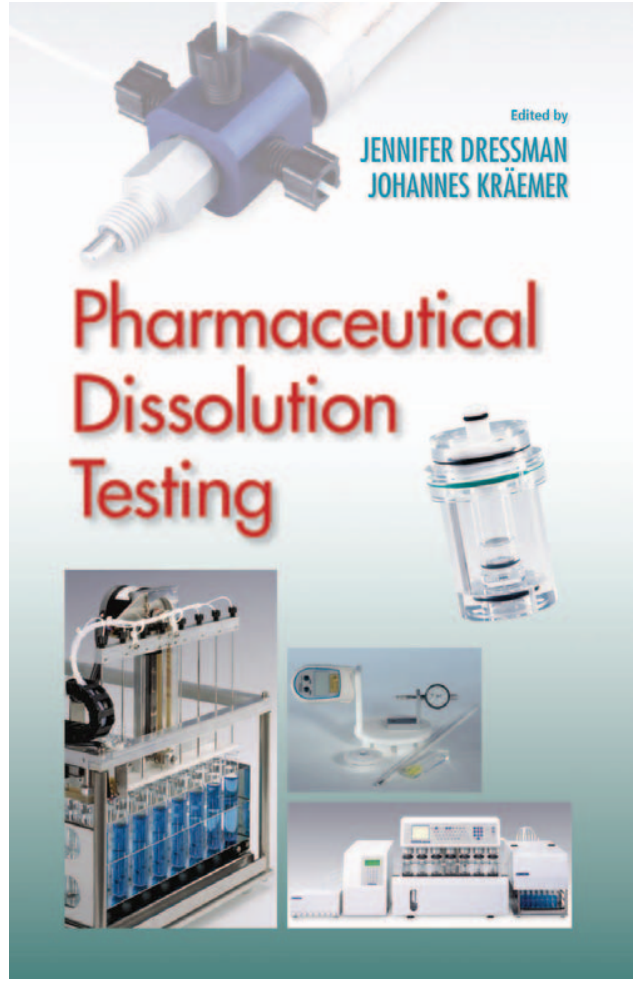

This book may be ordered online at the DT website at www.dissolutiontech.com. Price, including shipping, is $\$ 190.00$ for USA and $\$ 210.00$ for outside USA. Credit card payment is available. 